\section{A lógica da conversação na conversação sobre a lógica}

\section{RESUMO}

0 presente trabalho apresenta considerações sobre as contradições de sentidos que se obtém entre os níveis semântico e pragmático, a partir de um texto de Lewis Carroll. Segundo 0 autor, tais constatações são importantes para 0 entendimento das relações entre a racionalidade ao nível das regras lógicas e a racionalidade enquanto ato comunicativo.

\section{ABSTRACT \\ The present article intends to discuss the question of contradictory meanings obtained between the semantic and the pragmatic levels of enunciations, starting from a text written by Lewis Carroll. According to the author, these considerations are important for the understanding of the relationship between what rationality presuposes at the logical level and what rationality is assumed to be at the pragmatic, communicational level. \\ PALAVRAS-CHAVE / KEY WORDS \\ - Paradoxos (Paradoxes) \\ - Sentido (Meaning) \\ - Comunicação (Communication)}

UMA INTERESSANTE QUESTÃo de filosofia da linguagem são as inconsistências que podem ser identificadas quando o tema da racionalidade é explorado na interface entre o conteúdo do que é dito, ao nível semântico, e o implicado pela sua contextualização, ao nível pragmático. ${ }^{1}$

Lewis Carroll tem sido reconhecido pela sua contribuição aos fundamentos da Lógica, ao contextualizar, sob a forma de diálogos, importantes problematizações às bases do conhecimento racional. Um dos mais expressivos é o seu "What the tortoise said to Aquilles", em que L. Carroll considera as limitações do argumento dedutivo, metaforizadas através do confronto entre a obstinação de Aquiles pela expressão da racionalidade e a resistência cética da tartaruga. ${ }^{2}$

O que faço, no presente ensaio, são considerações sobre o dito paradoxo, contido no mencionado texto de L. Carroll, que julgo relevantes para o entendimento das relações entre a racionalidade ao nível das regras lógicas e a racionalidade enquanto ato comunicativo. ${ }^{3}$

I "O paradoxo" 4

O texto de L. Carroll pode ser resumido assim:

Dado um argumento (E) do tipo euclidiano como o abaixo:

\footnotetext{
A Duas coisas iguais a uma terceira são iguais entre si

B Os dois lados deste triângulo são iguais a um terceiro

Z Os dois lados deste triângulo são iguais entre si
}

poder-se-ia supor um diálogo - no caso, entre Aquiles e a Tartaruga - em que o 
primeiro tentaria estabelecer a absoluta racionalidade do argumento dedutivo e a segunda, a absoluta dependência de aceitação de tal argumento, se contextualizado.

Diz a Tartaruga:

- Suponho que o argumento E deva ser interpretado como ilustrando o necessário raciocínio de concluir que $Z$ é verdadeiro, desde que $A$ e $B$ sejam aceitos como verdadeiros, certo?

- Certo, diz Aquiles.

- Suponho, entretanto, que alguém poderia não aceitar $A$ e $B$ como verdadeiros ou, ainda, mesmo aceitando A e B como verdadeiros, não aceitar a proposição hipotética $C$ de que se $A$ e $B$ são verdadeiros, então $Z$ deve, também, sê-lo. Correto?

- Correto, confirma Aquiles.

- Suponha, finalmente, que eu não aceite $Z$, como você poderia forçar-me a isso? questiona a tartaruga.

- Bem, disse Aquiles, se você aceita A e $B$, devo pedir-lhe que aceite $C$.

- E se eu me recusar a isso? insiste a tartaruga. Mas tudo bem, eu aceito C, diz ela, desde que você a explicite como proposição que deve constar objetivamente do argumento. Certo?

- Certo, diz Aquiles, assumindo a necessidade de atender o pedido para fechar o raciocínio.

- De modo que agora tudo está pronto? Mas e se eu continuasse não aceitando $Z$ ? pergunta a tartaruga.

- Bem, diz Aquiles, mas se você aceitou $A, B$ e $C$ como verdadeiros, assim deve aceitar $Z$.

- Talvez (pensa ela), mas isso já é uma nova proposição hipotética, e eu só poderia aceitá-la se ela for explicitada; nada pode me obrigar a aceitar proposições que, mesmo verdadeiras, não foram asseridas; de modo que, por favor, explicite $\mathrm{D}$, a nova proposição hipotética.

II A questão puramente lógica
O argumento $T$, como originalmente formulado, apresenta uma forma lógicodedutiva válida, ou seja, nele não se segue conclusão falsa de premissas verdadeiras.

$$
\begin{aligned}
& \text { (A) }(\forall x)(\forall y)(\forall z)((x=z \wedge y=z) \rightarrow x=y) \\
& \text { (B) }(a=c) \wedge(b=c) \\
& \text { (Z) } a=b
\end{aligned}
$$

T, portanto, representa uma instância de um argumento-tipo cuja validade é determinada por uma propriedade da dedução, ou por uma regra metadedutiva (RM) cuja forma geral poderia ser a de que, se as premissas são aceitas como verdadeiras, delas decorre, por um processo inferencial válido, a aceitação da conclusão como verdadeira, o que, de fato, pode ser demonstrado como segue:

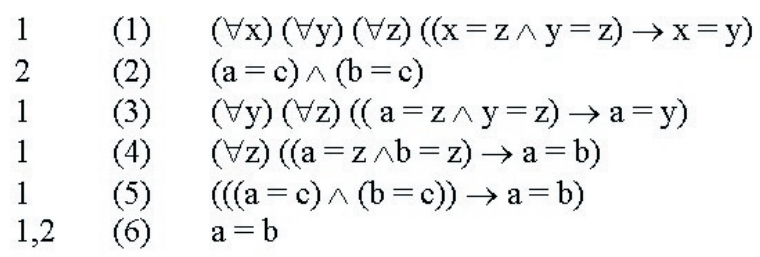

Que faz a tartaruga? Supõe a aparente ingenuidade de não aceitar $Z$ para provocar espertamente Aquiles e reconhecer a dependência que $\mathrm{T}$ tem de RM e, com isso, servir a L. Carroll, no sentido de explicitar o problema crucial, para a Filosofia da Lógica, da justificação das regras dedutivas. ${ }^{5}$

De fato, aquilo que a tartaruga chama de proposição hipotética $\mathrm{C}$ está ao nível da metalinguagem, à medida que regulamenta a inferência dedutiva válida do argumento $T$ na linguagem-objeto. Tal proposição hipotética $C$ é, então, a RM e passá-la para o nível da linguagem, na qualidade de premissa, como requer a tartaruga, é abrir o espaço metalingüístico necessário para que a mesma RM retorne, agora referindose a um argumento $\mathrm{T}$ com três premissas.

Como o que identifica o argumento dedutivo $\mathrm{T}$ é justamente a RM, no nível de metalinguagem, sempre haverá a 


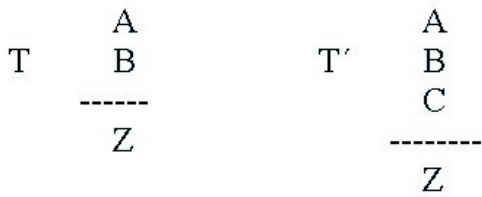

$$
\begin{aligned}
& \begin{array}{lll}
\mathrm{L}=\mathrm{T} & \mathrm{L}=\mathrm{T}{ }^{\prime} & \mathrm{L}=\mathrm{T}^{\prime}, \ldots \mathrm{n} \\
\mathrm{RM}=\mathrm{C} & \mathrm{RM}=\mathrm{D} & \mathrm{RM}=\mathrm{n}+1
\end{array}
\end{aligned}
$$

\section{A questão comunicativa}

Se, do ponto de vista lógico, a questão paradoxal poderia ser reduzida ao necessário ajuste entre linguagem e metalinguagem, absolutamente claro na arquitetura da construção formal, como foi possível o quase perfeito truque da tartaruga? Tudo, na verdade, parece ter origem na possibilidade de a metáfora de L. Carroll esconder níveis diferentes no mesmo plano da narrativa dialógica. Realmente, tudo se passa no contexto comunicativo e suas propriedades. Em tal contexto, por exemplo, há muito mais do que puras proposições ou conteúdos de sentenças declarativas. Há intenções informativas e comunicativas, há o dito e o implicado, há o semântico e o pragmático, há a Lógica standard e a Lógica não-trivial. A tartaruga expressa a intenção informativa de requerer $\mathrm{C}$, mas a comunicativa de implicar griceanamente a circularidade sem saída do argumento. T é Lógica de Predicados com Identidade. A inferência para além do dito é Lógica não-trivial.

Nessa perspectiva, a Lógica da conversação possui suas próprias regras, e essas não coincidem, evidentemente, com suas contrapartes puramente formais. $\mathrm{Na}$ Lógica standard, ou trivial, as regras da linguagem, ou da metalinguagem, estão a serviço da prova, da demonstração em que a validade, ou a agência do argumento, é tudo o que interessa. $\mathrm{Na}$ conversacional, a questão gira em torno da apreensão de intenções informativas e comunicativas. Aquiles e a Tartaruga, por exemplo, procuram tornar explícito o conjunto de informações e intenções virtualmente disponíveis no ambiente cognitivo em que estão inseridos. Mas tal condição não é gratuitamente garantida; ela depende, exatamente, de que as regras dessa lógica não-trivial envolvida sejam as mesmas. Em outras palavras, Aquiles e a Tartaruga podem estar sendo vítimas, em seus desacordos, de um duplo acidente, ao nível do argumento propriamente lógico e ao nível do argumento propriamente comunicativo.

Se o primeiro já foi pelo menos encaminhado, trata-se, agora, de sistematizar minimalmente o segundo.

Já de início, é preciso assumir que há um objeto, o argumento lógicodedutivo, que pode ser abstraído de qualquer situação comunicativa específica. Pode-se supor que $\mathrm{T}$ é uma instância de uma estrutura-tipo, uma construção lógico-dedutiva cuja propriedade central, a validade da passagem das premissas para a conclusão, é garantida por uma regra metalingüística, digamos $\mathrm{C}$. Isso é exatamente o que a seção anterior determina. Já no contexto de diálogo, entretanto, Aquiles e a Tartaruga convergem sobre T, cuja estrutura é explícita, mas divergem sobre RM, cuja função é pressuposta. Num primeiro momento, só se RM for aceita, $\mathrm{T}$ poderá sê-lo. T>>RM significa, na verdade, que RM não é uma regra do texto, mas do contexto e, como tal, não sendo asserida, não é nem verdadeira nem falsa, já que, por hipótese, não se instancia como uma proposição, mas como uma condição de possibilidade. E sobre uma condição não se pode exigir dela o reconhecimento de que seja verdadeira ou falsa, mas de que seja aceita ou não por relevante. De fato, T>>RM quer dizer, em última análise, que, só se RM for relevante, $T$ faz sentido. $A$, $B$ e $Z$ só se constituem como argumentos lógico-dedutivos à medida que RM é aceita 
como adequada. De modo que recusar RM, não é apenas recusar $T$, é nem constituílo. É exatamente esse sentimento que confunde o esforço de Aquiles. Ele intui que a objeção da Tartaruga não apenas invalida T. Ela constitui um T em estado de eterno processo. Se o contexto de RM não é aceito em sua função, então $T$ é uma estrutura incompleta. Se RM passa a fazer parte de T, como a Tartaruga o exige, então $T$ é uma estrutura por completar indefinidamente. Logo, T é sempre incompleto; e é isso que a Tartaruga quer O-implicar. Dito de outra forma, o que é pressuposto não pode, por hipótese, ser dito, e o que não pode ser dito, não pode ser aceito compulsoriamente. Dependerá de uma decisão a priori de aceitabilidade. A Tartaruga consegue, assim, dar, através de um exemplo clássico da Lógica standard, um exemplo clássico de uma propriedade standard da comunicação humana. Toda Lógica conversacional, mesmo num diálogo sobre Lógica, depende de acordos construídos sobre o bom senso, sem 0 qual não há lógica que resista e não há democracia que se sustente. Mas o acordo, e essa é a maior lição da Tartaruga, não se deduz a posteriori da racionalidade dos argumentos. Ele não é o resultado de um algoritmo irrecusável, mas de uma decisão a priori, de um ato de jogar racionalmente. O princípio da racionalidade não ocorre por uma demonstração lógico-dedutiva. Não, a dedução é que ocorre por um ato inaugural in advance de racionalidade.

\section{Notas}

1 Para uma forma de entender a distinção SemânticaPragmática, ver Levinson (83).

20 texto pode ser encontrado em Português na obra com o título Lewis Carroll: Aventuras de Alice no País das Maravilhas, Através do Espelho e o que Alice encontrou lá, da Summus Editorial, 1980.

3 Ainda que 0 tópico, em Lewis Carroll, possa servir a propósitos estritamente formais, a idéia básica, aqui, é explorá-lo na interface entre a proposição, tomada como livre de contexto, e 0 enunciado, enquanto ocorrência contextualizada.

40 termo "paradoxo", aqui, como aparece no próprio texto de L.Carroll, não está sendo tomado no sentido intrinsicamente formal.

5 Cf. o texto clássico de Susan Haack (76) "The Justification of Deduction", originalmente em Mind (85), reimpresso em R.I.G Hughes (93) ed. A Philosophicl Companion to First-Order Logic. Para interessantes considerações em outra direção, ver Dummett,M. (91) the Logical Basis of Metaphysics", especialmente capítulos 8 e 11. 